\title{
Droop-free controls of inverter-based generator for use in systems that interconnected with synchronous generators
}

\author{
Suchart Janjornmanit, Sakorn Panta, Wirat Nakkrongdee \\ Department of Electrical Engineering, Rajamangala University of Technology Lanna, Chiang Mai, Thailand
}

\begin{tabular}{l} 
Article Info \\
\hline Article history: \\
Received Jun 21, 2020 \\
Revised Mar 14, 2021 \\
Accepted Mar 19, 2021 \\
\hline
\end{tabular}

\section{Keywords:}

Active power control

Angle control

Microgrid

Power generation control

Reactive power control

\begin{abstract}
Because of its simplicity and autonomous operation, droop control technique is widely implemented for power generation control in microgrids. Despite its popularity, it has been reported that the technique has the stability problem. In this paper, the previous work of droop-free inverter-based generator designed for operating in a fix frequency islanded microgrid, is redesigned to have the ability to operate in both islanded and grid connected microgrid as well as to the main power grid where it interconnected with synchronous generators. The proposed voltage source inverters use phase locked loop (PLL) algorithm to synchronize the changing frequency due to the operation of the synchronous generator. Unlike the frequency droop control that the output frequency is varied as its active power changed, the proposed controls do not make an adjustment of the system frequency. This kind of operation reduces the chance of the system unstable due to severe frequency change and it also reduces the frequency deviation when it increases its active power output. Simulation and result of the meshed power network demonstrate the feasibility to implement the proposed controls in the real system.
\end{abstract}

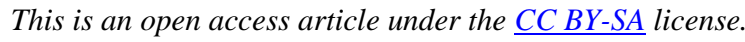

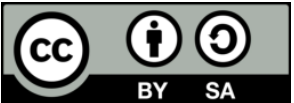

\section{Corresponding Author:}

Suchart Janjornmanit

Department of Electrical Engineering

Rajamangala University of Technology Lanna

128 Huay Kaew Road, A.Mueng, Chiang Mai, Thailand

Email: suchart@ rmutl.ac.th

\section{INTRODUCTION}

The widely used equipment for controlling the power generation by most of the renewable sources nowadays is the DC to AC power converter called the inverter. The significant number of the controls of the inverter-based generator adopts the control of power generation from the operation of synchronous generators. It is operated in such a way that the active power is generated by varying the output frequency where the reactive power is generated by varying output voltage amplitude. This kind of operation is called droop control technique, it is well known and gains popularity in the area of power generation controls in the microgrid. In order to gain its insight, readers may find the information related to droop control in [1]-[3]. Example of recent works on droop control can be found in [4]-[10]. It is also well known that the droop control has its drawbacks, and its main problem is the stability issues such as reported in [11]-[15]. The droop control needs to adjust its output frequency, and its severe changed frequency leads the system unstable. In order to mitigate this problem, it requires the communication channel for monitoring of system's parameters to maintain its stable operation by means of the coordinated droop gain adjustment among the other inverters. This kind of non-autonomous operation is avoided in the proposed controls in this paper. The proposed controls need no communication channel for any primary control of the inverter such as the gain adjustment 
because the proposed controls need no gain adjustment. It may need some form of communication only for the secondary control such as the adjustment of the referent output power and voltage of each inverter. The secondary control is not within the scope of this research. There are works introduced the droop-free control of power generation in the microgrid such as in [16]-[21]. The work in [16] avoids the use of droop by means of output impedance estimation, and controls each of inverter autonomously without the need of communication channel for primary control. However, the estimation does not guarantee the stability operation, there is no output impedance estimation needed when compared to the proposed controls. The works of droop-free control in [17]-[20] need the communication between the inverters to adjust its primary control. There is no communication needed when compared to the proposed control and each inverter-based generator works autonomously. Although the droop-free work in [21] solves the problem occurred during the incident of communication failures in a microgrid, it still needs the communication when the microgrid is partitioned.

In this paper, the previous work of power generation controls based on PID control of the adjustment of amplitude and phase of the output voltage in [22], is redesigned to operate in systems that the frequency is not a fixed value. The primary of this kind of control is introduced firstly in [23], but only the active power generation control is presented. In addition, the investigation is limited only to the redial network. The PV and PQ mode of operation of the inverter-based generator are proposed in this paper, and they were investigated in the meshed power network. The paper is organized as follows. The proposed droopfree inverters are detailed in the next section. The simulation results and discussion is in the subsequent section. The conclusion is given in the last section.

\section{THE PROPOSED DROOP-FREE INVERTERS}

The proposed control of power generation is shown in Figure 1. The inverter-based generator acts as the distributed generator (DG) supplying output power with an ability of regulating the output voltage in the PV mode of operation. The inverter is the voltage source inverter (VSI) that supplies generating voltage Vg to the output inductor $\mathrm{Lg}$. The output inductor is used to regulate the flow of power to the system while filtering out the discontinuity of the magnitude and phase changing. The inverter needs to generate voltage to follow the reference voltage from the reference voltage generator, which is where the proposed control is. The proposed controls are the reference voltage generators that generate the sinusoidal voltage reference in term of both magnitude and phase angle while preserving the system's frequency. The adjustment of the magnitude and phase of the reference voltage depends on the mode of operation of the DG. There are two modes of operation, PV and PQ control mode, proposed for the inverter-based generators which are sufficiently for the system that interconnected with synchronous generators. In addition, it should be that there is at least a synchronous generator that is operated in the swing control mode in that system.

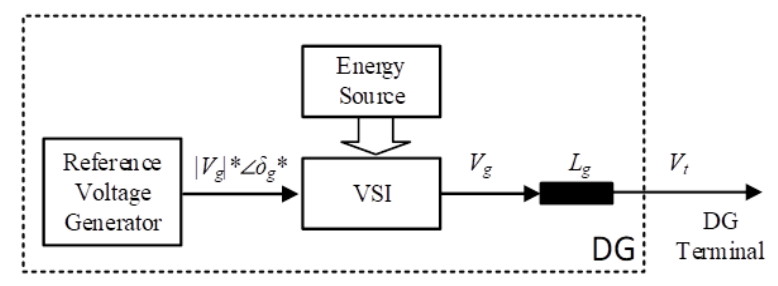

Figure 1. The proposed control of distributed generator

\subsection{PV control inverter}

Figure 2 shows the diagram of the reference voltage generator for an inverter that operates in the PV control mode. Unlike the controls in [22] where the system frequency is a fixed value, this inverter is designed to work with the synchronous generator where the frequency is always changed. The phase locked loop (PLL) is used to detect the frequency and phase angle of the sinusoidal waveform of the connected bus voltage. Unlike the operation of the droop control that the frequency of the output voltage is varied linearly to the active power output, the proposed control does not adjust its output frequency. The proposed control adjusts only its magnitude and phase angle of the generating voltage while preserving the frequency to its reading from the PLL. The using of the PLL in the proposed control intends to read the system's parameter only. The main point is that the proposed control does not adjust its output frequency, whereas the droop control does. This is why the droop control makes it directly influences the frequency stability problem, 
whereas the proposed controls do not. The recommended gain adjustments of the PI control of the terminal voltage $V_{t}$, like in [22], [23], are

$$
K_{p}=K_{i}=1
$$

The ratio of voltage magnitude at the front and the end of the output inductor is almost one. Therefore, the gain of proportional control is chosen as 1 . The integral control is added to guarantee the steady state operation. The $K_{i}$ is calculated by adapting from the PI gain adjustment by the favorite Siegler \& Nichols. The $K_{i}$ is the $K_{p}$ divided by 1.0T. T is chosen as 1 second, it is the time period of $1 \mathrm{~Hz}$ of undamped natural frequency of the expected response.

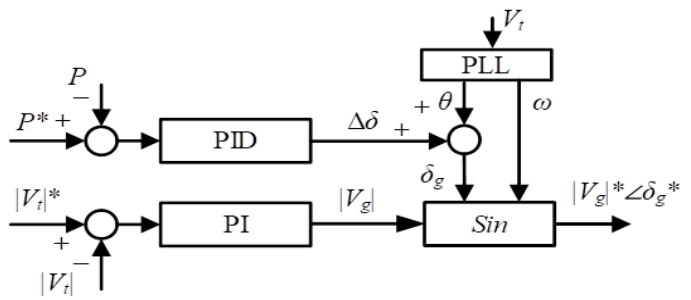

Figure 2. The reference voltage generator for PV control inverter are

The recommended gain adjustments of the PID control of active power output P, like in [22]-[23],

$$
\begin{aligned}
& K_{p}=0.1 \frac{X_{g}}{\left(\left|V_{b u s}\right|^{*}\right)^{2}} \\
& K_{i}=2 K_{p}
\end{aligned}
$$

and

$$
K_{d}=0.1 K_{p}
$$

The proportional gain $K_{p}$ is the approximation of the ratio of the active power delivered through the inductor and the voltage angle difference, the reader may find the relationship in [24] and [25]. The 0.1 in (2) is the assisting gain, meaning that the response of power should be reduced for waiting the response from the other DG interconnected in the system. The $K_{i}$ and $K_{d}$ are calculated by adapting from the PID gain adjustment by the Siegler \& Nichols. The $K_{i}$ is the $K_{p}$ divided by $0.5 \mathrm{~T}$ where the $K_{d}$ is the $K_{p}$ multiplied by $0.1 \mathrm{~T}$. $\mathrm{T}$ is chosen as 1 second, it is the time period of $1 \mathrm{~Hz}$ of undamped natural frequency of the expected response.

\subsection{PQ control inverter}

Figure 3 shows the diagram of the reference voltage generator for an inverter that operates in the PQ control mode. Unlike the control in [23] that the inverter-based generator controls only the active power output, the control of reactive power output is also proposed to work with the system that interconnected with synchronous generators in this paper. The PLL is also used in this mode of operation. The recommended gain adjustments of the PID control of the reactive power Q (for the fix frequency power system in [22] which are also applicable to the system that interconnected with the synchronous generator) are

$$
\begin{aligned}
& K_{p}=0.1 \frac{X_{g}}{\left|V_{\text {bus }}\right| *} \\
& K_{i}=2 K_{p}
\end{aligned}
$$

and,

$$
K_{d}=0.1 K_{p}
$$




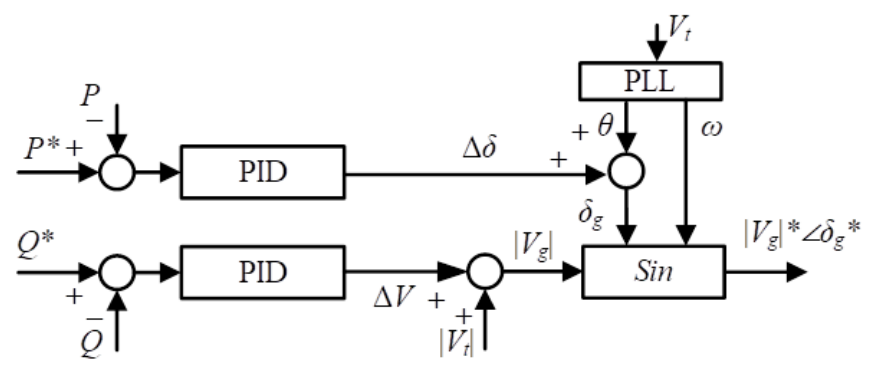

Figure 3. The reference voltage generator for PQ control inverter

The proportional gain $\mathrm{Kp}$ is the approximation of the ratio of the reactive power delivered through the inductor and the voltage magnitude difference, the reader may also find the relationship in [24] and [25]. The 0.1 in (5) is also the assisting gain. The $K_{i}$ and $K_{d}$ are also calculated by adapting from the PID gain adjustment by the Siegler \& Nichols. It can be calculated in the same manner as in the case of the active power. The recommended gain adjustments of the PID control of active power output $\mathrm{P}$ in this mode of operation are also the same as in the PV control mode.

\section{SIMULATION STUDY, RESULTS AND DISCUSSION}

The feasibility of implementing the proposed control is demonstrated by MATLAB/SIMULINK simulation. The 3-phase $380 \mathrm{~V} / 50 \mathrm{~Hz}$ meshed network of a microgrid is used to simulate the proposed inverter-based DGs interconnected with a synchronous generator. Figure 4 shows the demonstrated system. The system consists five buses of three DG buses and two load buses. The three DGs are a synchronous generator operating in swing control mode at the bus no.1, the proposed inverter-based generator operating in a PQ control mode at the bus no.3 and the proposed inverter-based generator operating in a PV control mode at the bus no.5. The line impedances are the combination of both inductive and resistive lines. The specification of generators and loads are detailed in Table 1. The per unit values in figures and tables are calculated using base $k V L L=0.38$ and base $M V A=1$. The set point of output power of the PQ control inverter is $P=1.75 p u$ and $Q=1 p u$ where the set point of PV control inverter is $P=1 p u$ and $V=1.02 p u$. The simulation results are shown in Tables 2-4; results of power in Table 2, results of power flow between buses in Table 3 and results of voltages in Table 4.

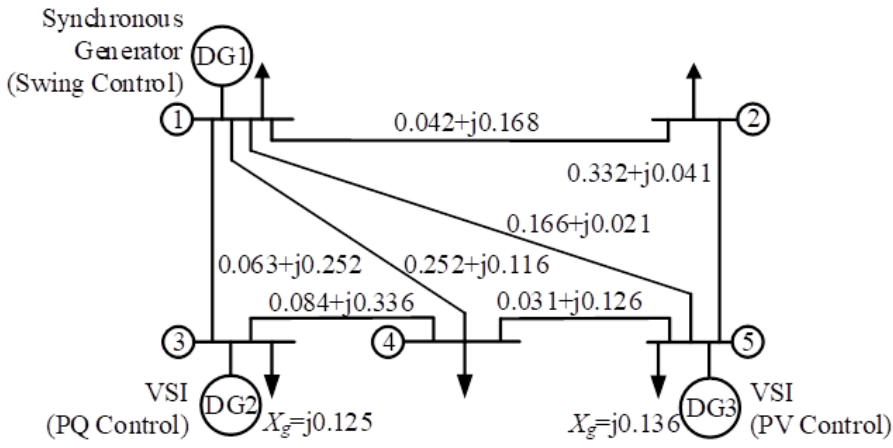

Figure 4. The configuration of the simulation system

It can be seen from Table 2 that the proposed inverters are able to control their power and voltage to the set points. The supplied power of PV and PQ inverters can be controlled to their specified values while the synchronous generator supplies the remaining of the loads. The system frequency deviates from the rated of $50 \mathrm{~Hz}$ to $49.64 \mathrm{~Hz}$, in other word the frequency deviation is $0.36 \mathrm{~Hz}$. This is the result of the normal operation of the synchronous generator, the proposed inverters do not make adjustment of the system frequency. Table 4 shows the results of voltages. It can be seen that the output voltage of the PV inverter can be controlled to its set point of 1.02pu. 
Table 1. Specification of generators and loads

\begin{tabular}{cccccccc}
\hline \multirow{2}{*}{ Bus } & \multicolumn{2}{c}{ Generation } & \multicolumn{2}{c}{ Load } & \multicolumn{2}{c}{ Voltage $\left(V_{t}\right)$} & \multirow{2}{*}{ Bus type } \\
& $\mathrm{P}(\mathrm{pu})$ & $\mathrm{Q}(\mathrm{pu})$ & $\mathrm{P}(\mathrm{pu})$ & $\mathrm{Q}(\mathrm{pu})$ & $\mathrm{pu}$ & Angle & Synchronous Generator, Swing Control \\
\hline 1 & no & no & 0.75 & 0.4 & 1.03 & $0^{\circ}$ & Load Bus \\
2 & $\ldots$ & $\ldots$. & 1.25 & 0.5 & no & no & VSI, PQ Control \\
3 & 1.75 & 1 & 0.6 & 0.3 & no & no & Load Bus \\
4 & $\ldots \ldots$ & $\ldots$. & 0.9 & 0.5 & no & no & VSI, PV Control \\
5 & 1 & no & 0.55 & 0.3 & 1.02 & no & \\
\hline
\end{tabular}

Table 2. Results of power

\begin{tabular}{ccccc}
\hline \multirow{2}{*}{ Bus } & $\mathrm{P}(\mathrm{pu})$ & $\mathrm{Q}(\mathrm{pu})$ & $\mathrm{P}(\mathrm{pu})$ & $\mathrm{Q}(\mathrm{pu})$ \\
\hline 1 & 1.43 & 0.305 & 0.78 & 0.41 \\
2 & $\ldots$ & $\ldots$. & 1.18 & 0.47 \\
3 & $1.75\left(\right.$ controlled, $\left.\Delta \delta=3.20^{\circ}\right)$ & 1 (controlled. $\Delta V=0.0333 \mathrm{pu})$ & 0.67 & 0.33 \\
4 & $\ldots$. & $\ldots$ & 0.91 & 0.50 \\
5 & $1\left(\right.$ controlled, $\left.\Delta \delta=2.06^{\circ}\right)$ & $0.86(\Delta V=0.0455 \mathrm{pu})$ & 0.57 & 0.31 \\
\hline *Result of system frequency is $49.64 \mathrm{~Hz}$ & & &
\end{tabular}

Table 3. Results of power flow between buses

\begin{tabular}{ccc}
\hline Line & $\mathrm{P}(\mathrm{pu})$ & $\mathrm{Q}(\mathrm{pu})$ \\
\hline Bus no.1 to Bus no.2 & 0.81 & 0.64 \\
Bus no.1 to Bus no.3 & -0.50 & -0.32 \\
Bus no.1 to Bus no.4 & 0.25 & -0.12 \\
Bus no.1 to Bus no.5 & 0.08 & -0.34 \\
Bus no. 2 to Bus no.5 & -0.39 & 0.11 \\
Bus no.3 to Bus no.4 & 0.58 & 0.35 \\
Bus no.4 to Bus no.5 & -0.09 & -0.32 \\
\hline
\end{tabular}

Table 4. Results of voltages

\begin{tabular}{ccccc}
\hline \multirow{2}{*}{ Bus } & \multicolumn{3}{c}{$V_{g}$} & \multicolumn{2}{c}{$V_{\text {bus }}$} \\
& pu. & Angle & pu. & Angle \\
\hline 1 & $\ldots$. & $\ldots$. & 1.0221 & $0^{\circ}$ \\
2 & $\ldots$. & $\ldots$. & 0.9768 & $-2.09^{\circ}$ \\
3 & 1.1090 & $5.08^{\circ}$ & 1.0567 & $-1.88^{\circ}$ \\
4 & $\ldots$. & $\ldots$. & 1.0059 & $-1.10^{\circ}$ \\
5 & 1.0655 & $3.13^{\circ}$ & 1.02 (controlled) & $-1.07^{\circ}$ \\
\hline *Result of system frequency is $49.64 \mathrm{~Hz}$
\end{tabular}

*Result of system frequency is $49.64 \mathrm{~Hz}$

In order to investigate its dynamic response, the system is simulated further by changing the set points of the inverters. At the beginning of $2^{\text {nd }}$ second, the set point of PQ inverter is changed from $P=$ $1.75 p u$ and $Q=1 p u$ to $P=2 p u$ and $Q=1.5 p u$. In addition, the set point of PV inverter is changed from $P=1 p u$ and $V=1.02 p u$ to $P=1.5 p u$ and $V=1.04 p u$. It should be noted that the supply active power is increased from the proposed inverters. Figure 5 shows the simulation results of the controlled values. It can be seen that the proposed inverters are able to control their power and voltage to the new set points. Figure 6 shows the result of system frequency. The system frequency changes from $49.64 \mathrm{~Hz}$ to $49.81 \mathrm{~Hz}$, in other word the frequency deviation reduced from $0.36 \mathrm{~Hz}$ to $0.19 \mathrm{~Hz}$. It demonstrates that the increasing power from the proposed inverters is the reducing of the frequency deviation. The reason is that whenever the supply of active power by the proposed inverter is increased then the supply of active power by the synchronous generator is decreased. The decreasing output power of the synchronous generator causes the synchronous generator more relax and its frequency would be increased closer to its rated frequency. The frequency deviation cannot be eliminated in the system that interconnected with the synchronous generator, which is where the source of frequency deviation is. The frequency deviation can be mitigated by the increasing of the output power from the proposed inverters. The droop control, like the synchronous generator, on the other hand, the increasing of the output power is also the increasing of the frequency deviation.

The ability of decreasing the frequency deviation of the proposed inverter benefits to systems that interconnected with the synchronous generator. Its benefit is not only for a microgrid, but also to the main grid where it connects to. There are many system unstable phenomena that caused by the severe frequency changed or large frequency deviation. The proposed inverters provide an alternative solution to this problem. The more the proposed inverters connecting to the system are the more system stable.

In summary, what are the benefits and what is new for the proposed controls. In general, the benefits of proposed controls are 1) droop-free controls (eliminates stability's issues due to the droop control); 2) the ability to connect to systems that interconnected with synchronous generators (both islanded and gridconnected microgrid, main grid); and 3) autonomous primary controls (need no communication channel for primary control). What is new when compared to [22] and [23]. Unlike the designs in [22] that the controls work only in the islanded microgrid and with a fixed system's frequency, the proposed controls have the ability to work with any kind of power system in general. Unlike the design in [23] that proposes only the grid-supporting inverter (PV), the PQ is also proposed in this article. In addition, whereas the investigation in [23] is limited to a simple radial network, the meshed network is investigated in the proposed controls. This article is an extended version of the short research paper in [23]. 


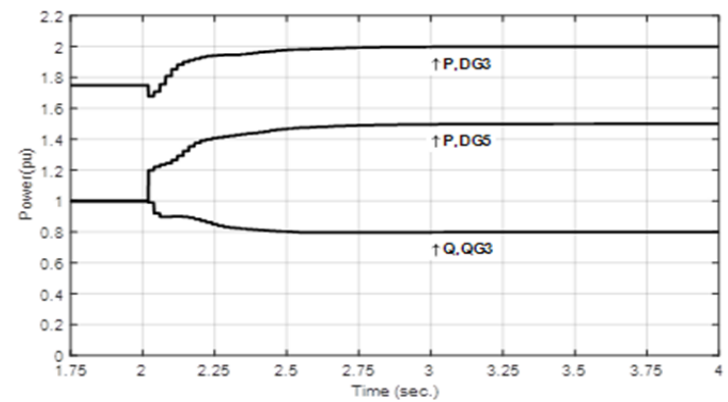

(a)

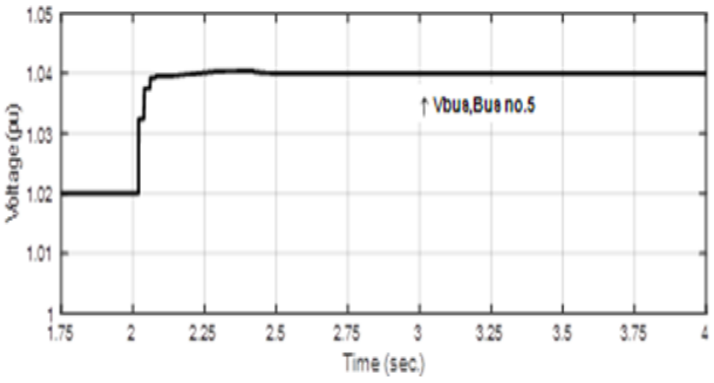

(b)

Figure 5. The results of controlled values, a) power, b) voltage

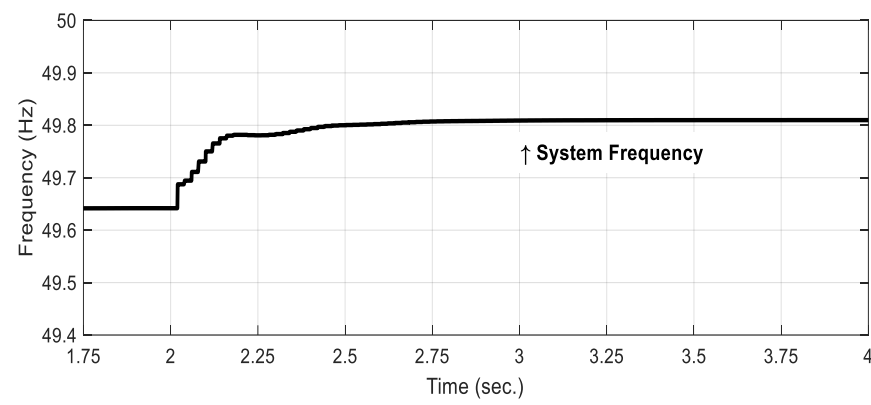

Figure 6. The results of system frequency

\section{CONCLUSION}

The droop-free inverter-based generators are proposed in this work. The PV and PQ mode of operation of the inverters are designed to operate in the power system that interconnected with the synchronous generator. The operational power systems are the islanded and grid-connected microgrid as well as to the main power grid, which means that it can be operated in any kind of power system. The proposed inverters operate without the need to communicate with the other DGs to adjust their primary control, it is operated autonomously. The inverter supplies no frequency adjustment when it generates active power and it reduces the chance of the system unstable due to severe frequency changed. As the trend of the growing number of inverter-based generators connected to the power system worldwide [26]-[27], the increasing number of this kind of inverters would provide a better performance in term of stable and communicationless operation of the power system in the future.

\section{REFERENCES}

[1] Y. Han, H. Li, P. Shen, E. A. A. Coelho and J. M. Guerrero, "Review of Active and Reactive Power Sharing Strategies in Hierarchical Controlled Microgrids," IEEE Transactions on Power Electronics, vol. 32, no. 3, pp. 2427-2451, March 2017, DOI: 10.1109/TPEL.2016.2569597.

[2] W. Ferreira de Souza, M.A. Severo-Mendes and L.A.C. Lopes, "Power sharing control strategies for a three-phase microgrid in different operating condition with droop control and damping factor investigation," IET Renewable Power Gener., vol. 9, no. 7 pp. 831-839, 2015, DOI: 10.1049/iet-rpg.2014.0250.

[3] M. S. Golsorkhi and D. D. C. Lu, "A Control Method for Inverter-Based Islanded Microgrids Based on V-I Droop Characteristics," IEEE Trans. Power Delivery, vol. 30, no. 3, pp. 1196-1204, 2015, DOI: 10.1109/TPWRD.2014.2357471.

[4] X. Meng, J. Liu and Z. Liu, "A Generalized Droop Control for Grid-Supporting Inverter Based on Comparison Between Traditional Droop Control and Virtual Synchronous Generator Control," IEEE Transactions on Power Electronics, vol. 34, no. 6, pp. 5416-5438, June 2019, DOI: 10.1109/TPEL.2018.2868722.

[5] Y. Sun et al., "An f-P/Q Droop Control in Cascaded-Type Microgrid," IEEE Transactions on Power Systems, vol. 33, no. 1, pp. 1136-1138, Jan. 2018, DOI: 10.1109/TPWRS.2017.2752646. 
[6] A. Yogarathinam and N. R. Chaudhuri, "Stability-Constrained Adaptive Droop for Power Sharing in AC-MTDC Grids," IEEE Transactions on Power Systems, vol. 34, no. 3, pp. 1955-1965, May 2019, DOI: 10.1109/TPWRS.2018.2890296.

[7] N. Vazquez, S. S. Yu, T. K. Chau, T. Fernando, and H. H. Iu, “A Fully Decentralized Adaptive Droop Optimization Strategy for Power Loss Minimization in Microgrids with PV-BESS," IEEE Transactions on Energy Conversion, vol. 34, no. 1, pp. 385-395, March 2019, DOI: 10.1109/TEC.2018.2878246.

[8] T. Hong, D. Zhao, Y. Zhang, B. Cui, and Y. Tian, "Optimal Voltage Reference for Droop-Based DERs in Distribution Systems," IEEE Transactions on Smart Grid, vol. 11, no. 3, pp. 2357-2366, May 2020, DOI: 10.1109/TSG.2019.2953154.

[9] F. Sun, J. Ma, M. Yu, and W. Wei, "A Robust Optimal Coordinated Droop Control Method for Multiple VSCs in AC-DC Distribution Network," IEEE Transactions on Power Systems, vol. 34, no. 6, pp. 5002-5011, Nov. 2019, DOI: 10.1109/TPWRS.2019.2919904.

[10] Y. Han and J. Ha, "Droop Control Using Impedance of Grid-Integrated DFIG within Microgrid," IEEE Transactions on Energy Conversion, vol. 34, no. 1, pp. 88-97, March 2019, DOI: 10.1109/TEC.2018.2861819.

[11] Y. Pan, L. Chen, X. Lu, J. Wang, F. Liu, and S. Mei, "Stability Region of Droop-Controlled Distributed Generation in Autonomous Microgrids," IEEE Transactions on Smart Grid, vol. 10, no. 2, pp. 2288-2300, March 2019, DOI: 10.1109/TSG.2018.2849084.

[12] A. S. Vijay, D. K. Dheer, A. Tiwari, and S. Doolla, "Performance Evaluation of Homogeneous and Heterogeneous Droop-Based Systems in Microgrid-Stability and Transient Response Perspective," IEEE Transactions on Energy Conversion, vol. 34, no. 1, pp. 36-46, March 2019, DOI: 10.1109/TEC.2018.2851031.

[13] L. Huang, H. Xin, Z. Wang, L. Zhang, K. Wu, and J. Hu, "Transient Stability Analysis and Control Design of Droop-Controlled Voltage Source Converters Considering Current Limitation," IEEE Transactions on Smart Grid, vol. 10, no. 1, pp. 578-591, Jan. 2019, DOI: 10.1109/TSG.2017.2749259.

[14] S. Wang, Z. Liu, J. Liu, D. Boroyevich, and R. Burgos, "Small-Signal Modeling and Stability Prediction of Parallel Droop-Controlled Inverters Based on Terminal Characteristics of Individual Inverters," IEEE Transactions on Power Electronics, vol. 35, no. 1, pp. 1045-1063, Jan. 2020, DOI: 10.1109/TPEL.2019.2914176.

[15] G. Raman and J. C. Peng, "Mitigating Stability Issues Due to Line Dynamics in Droop-Controlled Multi-Inverter Systems," IEEE Transactions on Power Systems, vol. 35, no. 3, pp. 2082-2092, May 2020, DOI: 10.1109/TPWRS.2019.2949311.

[16] A. Ovalle, G. Ramos, S. Bacha, A. Hably, and A. Rumeau, "Decentralized Control of Voltage Source Converters in Microgrids Based on the Application of Instantaneous Power Theory," IEEE Trans. Ind. Electron., vol. 62, no. 2, pp. 1152-1162, 2015, DOI: 10.1109/TIE.2014.2336638.

[17] V. Nasirian, Q. Shafiee, J. M. Guerrero, F. L. Lewis, and A. Davoudi, "Droop-Free Distributed Control for AC Microgrids," IEEE Transactions on Power Electronics, vol. 31, no. 2, pp. 1600-1617, Feb. 2016, DOI: 10.1109/TPEL.2015.2414457.

[18] Z. Wang, W. Wu, and B. Zhang, "A Distributed Quasi-Newton Method for Droop-Free Primary Frequency Control in Autonomous Microgrids," IEEE Transactions on Smart Grid, vol. 9, no. 3, pp. 2214-2223, May 2018, DOI: 10.1109/TSG.2016.2609422.

[19] J. M. Rey, P. P. Vergara, M. Castilla, A. Camacho, M. Velasco, and P. Martí, "Droop-free hierarchical control strategy for inverter-based AC microgrids," IET Power Electronics, vol. 13, no. 7, pp. 1403-1415, 2020, DOI: 10.1049/iet-pel.2019.0705.

[20] S. M. Mohiuddin and J. Qi, "Droop-Free Distributed Control for AC Microgrids with Precisely Regulated Voltage Variance and Admissible Voltage Profile Guarantees," IEEE Transactions on Smart Grid, vol. 11, no. 3, pp. 19561967, May 2020, DOI: 10.1109/TSG.2019.2945691.

[21] C. X. Rosero, M. Velasco, P. Martí, A. Camacho, J. Miret, and M. Castilla, "Active Power Sharing and Frequency Regulation in Droop-Free Control for Islanded Microgrids Under Electrical and Communication Failures," IEEE Transactions on Industrial Electronics, vol. 67, no. 8, pp. 6461-6472, Aug. 2020, DOI: 10.1109/TIE.2019.2939959.

[22] S. Janjornmanit, S. Panta, and V. Thonglek, "An approach of controlling the inverter-based generator for use in an islanded microgrid," International Journal of Power Electronics and Drive System (IJPEDS), vol. 11, no. 3, pp. 1610-1616, Sep. 2020, DOI: 10.11591/ijpeds.v11.i3.pp1610-1616.

[23] S. Janjornmanit and S. Panta, "Grid Supporting Inverter with Power-Angle Control for using in Power System that Interconnected with Synchronous Generator," 2020 8th International Electrical Engineering Congress (iEECON), Chiang Mai, Thailand, 2020, pp. 1-4, DOI: 10.1109/iEECON48109.2020.229468.

[24] J. Rocabert, A. Luna, F. Blaabjerg, and P. Rodríguez, "Control of Power Converters in AC Microgrids," IEEE Transactions on Power Electronics, vol. 27, no. 11, pp. 4734-4749, Nov. 2012, DOI: 10.1109/TPEL.2012.2199334.

[25] W. D. Stevenson, "Elements of Power System Analysis," Singapore: McGraw-Hill, pp. 206-208, 1982.

[26] A. Mohammed, S. S. Refaat, S. Bayhan, and H. Abu-Rub, "AC Microgrid Control and Management Strategies: Evaluation and Review," IEEE Power Electronics Magazine, vol. 6, no. 2, pp. 18-31, June 2019, DOI: 10.1109/MPEL.2019.2910292.

[27] B. Kroposki et al., "Achieving a 100\% Renewable Grid: Operating Electric Power Systems with Extremely High Levels of Variable Renewable Energy," IEEE Power and Energy Magazine, vol. 15, no. 2, pp. 61-73, March-April 2017, DOI: 10.1109/MPE.2016.2637122. 